Original

\title{
The effect of post space preparation in teeth obturated with Mineral Trioxide Aggregate evaluated using a fluid filtration system
}

\author{
Seyed Mohsen Jalalzadeh ${ }^{1)}$, Ahmad Mamavi ${ }^{1)}$, Elham Khoshbin ${ }^{1)}$, Vrginia Karapanou ${ }^{2)}$ \\ and Zahed Mohammadi ${ }^{1)}$ \\ ${ }^{1)}$ Department of Endodontics, Dental School, Hamadan University of Medical Sciences, Hamadan, Iran \\ ${ }^{2)}$ Department of Endodontics, Tufts University School of Dental Medicine, Boston, MA, USA
}

(Received 1 February and accepted 24 September 2010)

\begin{abstract}
The aim of this study was to evaluate the seal of a 4-mm Mineral Trioxide Aggregate (MTA) filling after post space preparation. Forty single-rooted premolar teeth without curved root anatomy and fractures were selected. The root length was standardized to $12 \mathrm{~mm}$ by removing excess from the apical end. The roots were instrumented to a $50 \mathrm{~K}$-file by the step-back technique. The roots were randomly divided into groups A and B, of fifteen each. In group A, the canals were obturated with $7 \mathrm{~mm}$ of white MTA. After $24 \mathrm{~h}, 3 \mathrm{~mm}$ of MTA was removed to simulate post space preparation using a long shank diamond round bur. In group B, the canals were filled with $4 \mathrm{~mm}$ of white MTA. All samples were attached to a fluid filtration device. Measurements $\left(\mu \mathrm{l} \mathrm{min}{ }^{-1} \mathrm{~cm} \mathrm{H}_{2} \mathrm{O}^{-1}\right)$ were taken every $2 \mathrm{~min}$, for $10 \mathrm{~min}$ and data were analyzed by an independent $t$-test $(P>0.05)$. Fluid transport averaged in groups $A$ and $B$ at $9.2 \times 10^{-4}$, and $11.8 \times 10^{-4} \mu \mathrm{l} \mathrm{min}^{-1} \mathrm{~cm} \mathrm{H}_{2} \mathrm{O}^{-1}$, respectively. Independent $t$-test showed no significant difference between the groups $(P<\mathbf{0 . 0 5})$. Removing set MTA using a round bur for post space preparation does not affect its sealing ability, when $4 \mathrm{~mm}$ of MTA remains. (J Oral Sci 52, 567-570, 2010)
\end{abstract}

Correspondence to Dr. Seyed Mohsen Jalalzadeh, Department of Endodontics, Dental School, Hamadan University of Medical Sciences, Shahid Fahmideh Blv., Hamadan, Iran

Tel: +98-8118354219

Fax: +98-8118354220

E-mail: jalalzadeh@umsha.ac.ir
Keywords: canal filling material; cutting; mineral trioxide aggregate; post space preparation; seal.

\section{Introduction}

Failure to achieve a well sealed root canal system is one of the most common causes of failure after root canal therapy (1). Recontamination of the root canal system must be prevented in order to ensure long-term clinical success. Various obturation materials have been used for sealing the root canals, but none of these materials ideally meet the required recommendations (2).

Mineral Trioxide Aggregate (MTA) has the biological and physical properties of an ideal filling material because of its antibacterial properties, bio-compatibility, and good sealing ability (2-5). Recently, MTA has been used as a canal obturation material in apexification procedures (6), in re-implanted permanent immature teeth with open apices (7), and in retained primary teeth without permanent successor (8). Furthermore, the use of MTA as a root canal filling material in permanent teeth with fully developed roots has been suggested $(2,6,9)$.

In endodontically treated teeth, success depends upon the quality of the endodontic treatment and on good marginal integrity of the coronal restoration, preventing microleakage $(10,11)$. Coronal seal may be destroyed in MTA-filled teeth over time by recurrent decay, fracture of the coronal restoration or fracture of tooth crown (9), requiring the tooth to be retreated. Often the coronal structure of these teeth is inadequate and there is need for 
a post to reinforce coronal restorations. Sealing ability may be affected by the technique adopted for root filling reduction, the length and quality of the remaining root canal filling, and the timing of post space preparations (12). Earlier, few studies compared the effect of apical resection of set MTA on its sealing ability $(2,13,14)$. Andelin et al. found no significant differences in dye leakage between teeth with apically resected MTA and those with retrograde filling (13). Moreover, Lamb et al. reported that apical root resection did not significantly affect the sealing ability of MTA-filled canals when at least $3 \mathrm{~mm}$ of the MTA remained (2).

To date, few studies have compared the effect of orthograde MTA removal simulating post space preparation procedures on microleakage of canals filled with MTA. The aim of this study was to evaluate the effect of post space preparation on apical microleakage, in teeth obturated with MTA using a fluid filtration system.

\section{Materials and Methods}

\section{Tooth specimen selection and preparation}

Forty extracted single-rooted premolar teeth were used in the study. All teeth were stored in $2.5 \%$ sodium hypochlorite for $2 \mathrm{~h}$ to remove remnant soft tissue and then preserved in normal saline. Radiographs had been taken and the teeth were carefully selected to exclude those with root caries and other defects, as well as curved root anatomy. Additional exclusion criteria included teeth with multiple canals or calcification and previously root-filled teeth or those with anatomical abnormalities. The apices were removed by cutting $2 \mathrm{~mm}$ from the apical root end and then, the crowns and part of the cervical root area, if necessary, were removed with a fissure bur and water spray high-speed hand piece producing a standardized $12-\mathrm{mm}$ root length. The roots were instrumented to a 50 K-file (MANI ${ }^{\circledR}$, Utsunomiya, Japan) and shaped using the step-back technique at 0.5 -mm increments up to 80 K file (MANI ${ }^{\circledR}$ ). Gates Glidden drills \#3 and \#4 (MANI ${ }^{\circledR}$ ) were used to enlarge the middle and coronal portions of the roots. To simulate divergent open apices, all the canals were instrumented from the apex access using ProFile ${ }^{\circledR}$ \#40 .06 taper (DENSPLY Tulsa Dental, Johnson City, TN, USA) rotary files \#40, to working length of $16 \mathrm{~mm}$; the diameter of the specific file at $16 \mathrm{~mm}$ is $1.36 \mathrm{~mm}$, so the apical opening size was standardized to $1.36 \mathrm{~mm}$ in all the roots (6). Two milliliters of $1.3 \%$ sodium hypochlorite solution was used as an irrigant during instrumentation. Following instrumentation, all canals were rinsed with normal saline, dried with paper points, and divided in two experimental groups A and B of fifteen samples each. Five positive control teeth did not receive any filling materials after instrumentation. Five negative control teeth were not instrumented, but were completely sealed with cyanoacrylate glue and nail varnish at the apical portion. The apical portion of the teeth was inserted into a box filled with wet foam to simulate spongy bone.

\section{Obturation with MTA \\ Group A:}

White ProRoot ${ }^{\circledR}$ MTA (Dentsply Tulsa Dental, Tulsa, OK, USA), mixed according to the manufacturer's recommendations, was delivered with a messing gun into the canals, and compacted in layers with \#3 and \#4 endodontic pluggers (Dentsply Maillefer, Ballaiques, Switzerland). The canals were obturated with $7 \mathrm{~mm}$ of white ProRoot MTA in the orthograde manner with slight hand pressure. Radiographs were taken to confirm adequacy of the apical filling. If improper adaptation and integrity defects were detected radiographically, MTA was removed and the canal was re-obturated. Moist cotton pellets were placed over the MTA filling to facilitate setting of the material. The teeth were stored in wet gauze for $24 \mathrm{~h}$ at room temperature in a sealed container.

The cotton pellets were removed from the teeth $24 \mathrm{~h}$ later and the setting of MTA was determined to be adequate. Subsequently, $3 \mathrm{~mm}$ of MTA was removed from the access cavity, using a high-speed long shank diamond round \#2 bur (D+Z, Lemgo, Germany) and water coolant spray, simulating post space preparation. The bur was placed for one second on the surface of the MTA; then the canal space was irrigated with normal saline and dried with an air syringe. The process was repeated until $4 \mathrm{~mm}$ of MTA remained in the canals.

\section{Group B.}

The teeth were obturated orthogradely with 4-mm white ProRoot MTA in a manner similar to the method described for group A. Wet cotton pellets were placed on top of the MTA for setting. Teeth were stored in wet gauze for $24 \mathrm{~h}$ at room temperature.

All procedures were performed by one operator and the fluid filtration assay was performed blindly.

\section{Fluid filtration assay:}

The teeth were prepared for evaluation of leakage $48 \mathrm{~h}$ later using a fluid filtration system as described by Derkson et al. (15). Stainless steel tubing was placed through the center of a Plexiglas disk. The flattened occlusal surface of the root was attached to the lower surface of the Plexiglas disk connecting the roots to the stainless steel tube. All junctions and interfaces between the roots and tubing/disks were sealed with cyanoacrylate cement and epoxy resin. Using a polyethylene tube and a retainer, the stainless steel tube was connected to a $100-\mu 1$ micropipette 
(Microcaps; Fisher Scientific, Pittsburgh, PA, USA) with $0.001 \mathrm{ml}(1 \mu \mathrm{l})$ accuracy that was connected to a pressure chamber with water pressurized at $24 \mathrm{psi}$ (1.6 atm). An air bubble was introduced into the tubing using a 1-ml microsyringe (Becton-Dickinson, Madrid, Spain) until it reached the pipette. Movement of the air bubble inside the pipette was measured. To allow relaxation of the tubing before taking a reading, a 5-min pressurization preload was allowed. The measurements were taken every $2 \mathrm{~min}$, for an overall period of $10 \mathrm{~min}$ and the results were averaged. To give a comparative unit in microliters per minute per $24 \mathrm{psi}$, with the controls in $\mu \mathrm{l} \mathrm{min}^{-1} \mathrm{cmH}_{2} \mathrm{O}^{-1}$, the micro leakage values were divided by $1630 \mathrm{cmH}_{2} \mathrm{O}$ (which is equivalent to $24 \mathrm{psi}$ ). Micro leakage was expressed in $\mu \mathrm{l}$ $\min ^{-1} \mathrm{cmH}_{2} \mathrm{O}^{-1}(6,16)$.

The data were analyzed using the independent t-test with a significance level of $P<0.05$.

\section{Results}

Samples in the negative control group did not leak, while those in the positive group showed excessive fluid transport.

Group A, in which the 7-mm MTA filling was reduced to $4 \mathrm{~mm}$, exhibited a mean leakage flow of $9.2 \times 10^{-4} \pm$ $3.8 \times 10^{-4} \mu \mathrm{lmin}^{-1} \mathrm{cmH}_{2} \mathrm{O}^{-1}$. Group B, in which 4-mm MTA filling was placed during the obturation process, presented a mean leakage flow of $11.8 \times 10^{-4} \pm 10.6 \times 10^{-4} \mu \mathrm{l} \mathrm{min}^{-1}$ $\mathrm{cmH}_{2} \mathrm{O}^{-1}$. Analysis of data with an independent $t$-test showed no significant differences between group $\mathrm{A}$ and group B $(P=0.38)$.

\section{Discussion}

Hydraulic conductance of canals obturated with a 4-mm orthograde MTA filling was $11.8 \times 10^{-4} \mu \mathrm{min}^{-1} \mathrm{cmH}_{2} \mathrm{O}^{-1}$. This is similar to that obtained by Lamb et al. with a 6mm orthograde MTA filling (2) and by Johnson et al. with other root end filling materials (17). Lamb et al. also demonstrated no significant difference in fluid transport between 3- and 6-mm MTA fillings (2).

Yildirim et al. reported that the sealing ability of MTA was superior when the smear layer was present (18). This finding may provide an explanation for the slightly less hydraulic conductance of canals in group A than in group B. The smear layer produced in group A may account for this result.

It is important that the root canal space is not damaged while the post space is being prepared. Boutsioukis et al. could not retreat canals filled with MTA, using a GT rotary instrument (19). Rotary instruments may not be the best choice for post space preparation in MTA obturated canals. Nickel-Titanium instruments lack the resistance necessary to overcome MTA surface hardness. Another important factor may be the process of MTA placement in the canals, and the way this affects physical properties of MTA. According to Nekoofar et al. (20), high pressure during condensation was found to play an interesting role in increasing the surface hardness of MTA; thus, by compacting the material and reducing voids and microchannels that pick up water, it becomes less likely for MTA to set appropriately. In the present study, we lightly condensed MTA by hand in order to obtain a lightly compacted defect-free MTA filling. Moreover, in the present study, the root canal space was enlarged during the instrumentation phase in order to standardize the apical opening to $1.36 \mathrm{~mm}$. For post space preparation, the use of a long shank round bur of appropriate size, as used in this study, or thin ultrasonic tips may be helpful; however, further research is needed to investigate which technique provides maximum seal with minimum damage. The risk of root perforation or ultrasonic tip separation should be considered when selecting the appropriate instrument size.

Yildirim et al. measured sealing ability of MTA in teeth with post indication and compared it with canals filled with gutta-percha and AH-Plus sealer. They found that a 5-mm MTA filling had less microleakage than 5-mm gutta percha and AH-Plus sealer teeth with closed apices, suggesting that the superior sealing properties of MTA should be valued and considered for obturation in teeth that need post preparation and build-up, as well (21). In agreement with Yildirim's study, we found that cutting of MTA did not affect the sealing ability of MTA. There are limitations to be considered that can modify the application of our methods, such as the depth of canal filling, accessibility to canal filling material, and size of the bur in relationship to canal space and shape and caution must be exercised when conclusions are drawn from the results of this study. Considering the limitations of this study, it can be concluded that cutting of set MTA does not have a destructive effect on the sealing ability of orthograde MTA filling of canals if $4 \mathrm{~mm}$ of MTA remains.

\section{References}

1. Veríssimo DM, do Vale MS (2006) Methodologies for assessment of apical and coronal leakage of endodontic filling materials: a critical review. J Oral Sci 48, 93-98.

2. Lamb EL, Loushine RJ, Weller RN, Kimbrough WF, Pashley DH (2003) Effect of root resection on the apical sealing ability of mineral trioxide aggregate. Oral Surg Oral Med Oral Pathol Oral Radiol Endod 95, 732-735.

3. Torabinejad M, Hong CU, Pitt Ford TR, Kettering 
JD (1995) Antibacterial effects of some root end filling materials. J Endod 21, 403-406.

4. Yildirim T, Gençoğlu N, Firat I, Perk C, Guzel O (2005) Histologic study of furcation perforations treated with MTA or Super EBA in dogs' teeth. Oral Surg Oral Med Oral Pathol Oral Radiol Endod 100, 120-124.

5. Lee SJ, Monsef M, Torabinejad M (1993) Sealing ability of a mineral trioxide aggregate for repair of lateral root perforations. J Endod 19, 541-544.

6. Martin RL, Monticelli F, Brackett WW, Loushine RJ, Rockman RA, Ferrari M, Pashley DH, Tay FR (2007) Sealing properties of mineral trioxide aggregate orthograde apical plugs and root fillings in an in vitro apexification model. J Endod 33, 272275.

7. Jacobovitz M, de Pontes Lima RK (2009) The use of calcium hydroxide and mineral trioxide aggregate on apexification of a replanted tooth: a case report. Dent Traumatol 25, E32-36.

8. O'Sullivan SM, Hartwell GR (2001) Obturation of a retained primary mandibular second molar using mineral trioxide aggregate: a case report. J Endod 27, 703-705.

9. Al-Hezaimi K, Naghshbandi J, Oglesby S, Simon JHS, Rotstein I (2005) Human saliva penetration of root canals obturated with two types of mineral trioxide aggregate cements. J Endod 31, 453-456.

10. Kayahan MB, Malkondu O, Canpolat C, Kaptan F, Bayirli G, Kazazoglu E (2008) Periapical health related to the type of coronal restorations and quality of root canal fillings in a Turkish subpopulation. Oral Surg Oral Med Oral Pathol Oral Radiol Endod 105, E58-62.

11. Siqueira JF Jr, Rôças IN, Alves FRF, Campos LC (2005) Periradicular status related to the quality of coronal restorations and root canal fillings in a Brazilian population. Oral Surg Oral Med Oral Pathol Oral Radiol Endod 100, 369-374.

12. Fan B, Wu MK, Wesselink PR (1999) Coronal leakage along apical root fillings after immediate and delayed post space preparation. Endod Dent Traumatol 15, 124-126.

13. Andelin WE, Browning DF, Hsu GHR, Roland DD, Torabinejad M (2002) Microleakage of resected MTA. J Endod 28, 573-574.

14. Apaydin ES, Shabahang S, Torabinejad M (2004) Hard-tissue healing after application of fresh or set MTA as root-end-filling material. J Endod 30, 2124.

15. Derkson GD, Pashley DH, Derkson ME (1986) Microleakage measurement of selected restorative materials - a new in vitro method. J Prosthet Dent $56,435-440$.

16. Bachicha WS, DiFiore PM, Miller DA, Lautenschlager EP, Pashley DH (1998) Microleakage of endodontically treated teeth restored with posts. J Endod 24, 703-708.

17. Johnson JR, Anderson RW, Pashley DH (1995) Evaluation of the seal of various amalgam products used as root-end fillings. J Endod 21, 505-508.

18. Yildirim T, Oruçoğlu H, Cobankara FK (2008) Long-term evaluation of the influence of smear layer on the apical sealing ability of MTA. J Endod 34, 1537-1540.

19. Boutsioukis C, Noula G, Lambrianidis T (2008) Ex vivo study of the efficiency of two techniques for the removal of mineral trioxide aggregate used as a root canal filling material. J Endod 34, 12391242.

20. Nekoofar MH, Adusei G, Sheykhrezae MS, Hayes SJ, Bryant ST, Dummer PM (2007) The effect of condensation pressure on selected physical properties of mineral trioxide aggregate. Int Endod J 40, 453461.

21. Yildirim T, Taşdemir T, Orucoglu H (2009) The evaluation of the influence of using MTA in teeth with post indication on the apical sealing ability. Oral Surg Oral Med Oral Pathol Oral Radiol Endod 108, 471-474. 